\title{
Multiple aneurysms in subarachnoid hemorrhage - identification of the ruptured aneurysm, when the bleeding pattern is not self-explanatory - development of a novel prediction score
}

Alexis Hadjiathanasiou ${ }^{1 *} \mathbb{D}$, Patrick Schuss ${ }^{1}$, Simon Brandecker ${ }^{1}$, Thomas Welchowski ${ }^{2}$, Matthias Schmid ${ }^{2}$, Hartmut Vatter ${ }^{1}$ and Erdem Güresir ${ }^{1}$

\begin{abstract}
Background: In aneurysmal subarachnoid hemorrhage (SAH) and multiple intracranial aneurysms (MIAs) identification of the bleeding source cannot always be assessed according to the hemorrhage pattern. Therefore, we developed a statistical model for the prediction of the ruptured aneurysm in patients with SAH and multiple potential bleeding sources at the time of ictus.

Methods: Between 2012 and 2015, 252 patients harboring 619 aneurysms were admitted to the authors' institution. Patients were followed prospectively. Aneurysm and patient characteristics, as well as radiological findings were entered into a computerized database. Gradient boosting techniques were used to derive the statistical model for the prediction of the ruptured aneurysm. Based on the statistical prediction model, a scoring system was produced for the use in the clinical setting. The aneurysm with the highest score poses the highest possibility of being the bleeding source. The prediction score was then prospectively applied to 34 patients suffering from SAH and harboring MIAs.

Results: According to the statistical prediction model the main factors affecting the rupture in patients harboring multiple aneurysms were: 1) aneurysm size, 2) aneurysm location and 3) aneurysm shape. The prediction score identified correctly the ruptured aneurysm in all the patients that were used in the prospective validation. Even in the five most debatable and challenging cases assessed in the period of prospective validation, for which the score was designed for, the ruptured aneurysm was predicted correctly.
\end{abstract}

Conclusions: This new and simple prediction score might provide additional support for neurovascular teams for treatment decision in SAH patients harboring multiple aneurysms. In a small prospective sample, the prediction score performed with high accuracy but larger cohorts for external validation are warranted.

Keywords: Multiple intracranial aneurysms, Rupture prediction, Subarachnoid hemorrhage

\footnotetext{
* Correspondence: alexis.hadjiathanasiou@ukb.uni-bonn.de

'Department of Neurosurgery, Rheinische Friedrich-Wilhelms-University, Sigmund-Freud-Str. 25, 53127 Bonn, Germany

Full list of author information is available at the end of the article
}

C C The Author(s). 2020 Open Access This article is licensed under a Creative Commons Attribution 4.0 International License, which permits use, sharing, adaptation, distribution and reproduction in any medium or format, as long as you give appropriate credit to the original author(s) and the source, provide a link to the Creative Commons licence, and indicate if changes were made. The images or other third party material in this article are included in the article's Creative Commons. licence, unless indicated otherwise in a credit line to the material. If material is not included in the article's Creative Commons licence and your intended use is not permitted by statutory regulation or exceeds the permitted use, you will need to obtain permission directly from the copyright holder. To view a copy of this licence, visit http://creativecommons.org/licenses/by/4.0/ The Creative Commons Public Domain Dedication waiver (http://creativecommons.org/publicdomain/zero/1.0/) applies to the data made available in this article, unless otherwise stated in a credit line to the data. 


\section{Background}

Up to $20 \%$ of patients suffering from aneurysmal subarachnoid hemorrhage (SAH) are harboring multiple intracranial aneurysms (MIAs) [1,2]. The bleeding source can be assessed by cranial imaging findings, e.g. according to the pattern of the hemorrhage in computed tomography $(\mathrm{CT})$ in most cases. Nehls et al. described an algorithm in 1985 helping to identify the ruptured aneurysm according to mainly imaging findings [3]. However, according to this algorithm the ruptured aneurysm was identified with the highest accuracy when focal accumulation of blood in CT was seen in proximity to the ruptured aneurysm. While in such cases treatment decision of the ruptured aneurysm is unambiguous, in some cases with no definite hemorrhage pattern the identification of the ruptured aneurysm can be challenging, for example, when the hemorrhage pattern has no lateralization and two or more aneurysms are in immediate proximity. As a result of this issue, we developed a statistical model for the prediction of the ruptured aneurysm, which could provide support in daily clinical routine for neurovascular teams.

\section{Methods}

\section{Study population}

Between 2012 and 2015, 252 patients harboring 619 aneurysms were admitted to the authors' institution. SAH was diagnosed by $\mathrm{CT}$ or lumbar puncture. CT-angiography (CT-A) and additional digital subtraction angiography (DSA) were performed in order to identify the bleeding source. Information, including patient characteristics on admission and during treatment course, treatment modality, aneurysm size, shape, location and further radiological features, were collected prospectively and entered into a computerized database. Exclusion criteria were (1) insufficient quality of CT-A/DSA to evaluate aneurysm shape or size, and (2) the presence of fusiform, mycotic or partially thrombosed aneurysms. Follow up was standardized for all patients with clinical follow ups at 6,12 months and then annually. At 6 months the first follow up was combined with DSA and MRI (magnetic resonance imaging), which was then repeated annually. All aspects of this study were approved by the local ethics committee and because of the character of the study, patient consent was not required.

\section{Identification of the ruptured aneurysm}

The ruptured aneurysm was treated in all patients with SAH. The neurovascular team at the authors' institution identified the aneurysm with the highest rupture probability according to the CT findings (i.e. pattern of hemorrhage, intracerebral hemorrhage (ICH)) and aneurysm characteristics (shape, size, location) on patient admission. In order to standardize the definition of aneurysm shape, all multilobulated aneurysms or aneurysms with a bleb were considered as irregularly shaped; all others were considered as regularly shaped. In uncertain cases, the aneurysm shape was decided in an interdisciplinary meeting of the neurovascular team.

According to the findings, treatment of the presumably ruptured aneurysm was performed.

After treatment, validation of the prediction score was performed in two ways: surgically treated aneurysms were directly inspected, and the bleeding source was identified. In endovascularly treated aneurysms the identification of the ruptured aneurysm in the prospective cohort was made according to the bleeding pattern or further CT findings, e.g. ICH and long-term follow-up. The bleeding source, i.e. the ruptured aneurysm, was unambiguous in all aneurysms treated endovascularly.

\section{Evaluation of the prospective cohort after development of the score}

Independent of the decision of the neurovascular team, and independent to the aneurysm treatment, information of all aneurysms (aneurysm size, location and shape) included in the prospective validation were transferred from the neuroradiologist to an author $(\mathrm{AH})$ in written form for the calculation of the prediction score.

\section{Data}

Aneurysm location was divided into five regions in order to simplify the scoring system: anterior cerebral artery (AA) including anterior communicating artery (AcomA), internal carotid artery excluding posterior communicating artery (ICA), posterior communicating artery (PcomA), middle cerebral artery (MCA), and the posterior circulation. The maximum aneurysm diameter was defined as aneurysm size. Furthermore, aneurysm shape was categorized in regular and irregular shape. Irregular shape was defined if the aneurysm was lobulated or a bleb was found. All other cases were defined as regular shaped aneurysms.

For statistical analysis each aneurysm was treated as a separate observation, implying that each of the patients could contribute several observations (= aneurysms) to the analysis data set. The outcome variable for each observation was binary (rupture / no rupture). Some of the predictor variables, namely size, shape and location, varied across the aneurysms. Additionally, patient-specific predictor variables were considered, e.g., age, smoking status, hypertension (AHT), number of aneurysms per patient and number of additional aneurysms per region. Only one variable (namely the shape of aneurysm) contained missing values. The number of missing values in this variable was 23 (2.91\%). Due to this very low number, and since all other variables were completely observed, we did not apply multiple imputation but choose the more straightforward approach of imputing missing aneurysm shapes by single logistic regression conditional on all other variables (imputed values: 18 regular and 
five irregular). After derivation of the score, the score was prospectively validated in a consecutive cohort of patients with SAH and MIAs.

\section{Statistical analysis}

A component-wise gradient boosting algorithm with linear base learners [4] was used to derive the prediction score. This modeling approach simultaneously selects variables that are relevant for prediction and estimates the relationship between the outcome and the predictor variables. A binomial distribution with logistic link function was used to account for the binary structure of the outcome. Of note, the statistical model underlying the gradient boosting approach is defined in terms of a score that has exactly the same structure and interpretation as the linear score of a classical logistic regression model. Compared to the latter approach, the main difference (and advantage) of the gradient boosting approach is the algorithmic procedure that is used to fit the logistic model (i.e., to estimate its coefficients). In particular, gradient boosting contains the aforementioned built-in procedure for data-driven variable selection. We note that major overfitting issues due to variable selection are unlikely in this case, as the number of patients $(n=252)$ is sufficiently large compared to the number of candidate variables (10, i.e. 25 patients per variable). In addition, to counteract the variability induced by variable selection, the coefficient estimates obtained from gradient boosting are regularized such that they automatically improve predictive performance and reduce overfitting. The coefficients of logistic regression are included in the search space as a special case of the more flexible gradient boosting model. By definition, the prediction function of our model included an aneurysm-specific part ("prediction score"), which was given by a linear combination of the variables size, shape and location of the aneurysm. It also included a patient-specific part that was given by a linear combination of age, smoking status, AHT, number of aneurysms per patient and number of additional aneurysms per region. To account for the fact that some patients had multiple aneurysms whose measurements may be dependent, a patient-specific random effect was included in the boosting model [5].

For prediction, the boosting model was used to compute the rupture probabilities for all aneurysms. These predicted probabilities included all variables selected for the model, i.e., aneurysm-specific and patient-specific variables. For each patient the aneurysm with maximum probability was predicted as the one to rupture. Note that the probabilities of rupture directly correspond to the magnitude of the aforementioned aneurysm-specific part of the model's prediction function. On the patient level (where patient-specific variables such as age are constant), a simplified strategy is therefore to predict the aneurysm with maximum value of the aneurysm-specific prediction score as the one to rupture.

To evaluate the prediction accuracy of the proposed scoring system, ten-fold cross-validation was carried out (Fig. 1) [6]. To this purpose, the data were subdivided into ten mutually exclusive subsets ("folds") of equal size. Patients in each fold were used to evaluate a boosting model fitted to the union of the respective other nine folds ("learning samples"). Predictions were evaluated on the patient level by (i) selecting the aneurysm that was predicted to rupture according to the value of its aneurysm specific prediction score, as described above, and (ii) by evaluating whether the selected aneurysm coincided with the true ruptured aneurysm. Prediction accuracy was summarized by considering the percentages of correctly classified ruptures on the patient level. In addition, the area under the receiver operating characteristic curve (AUC) was calculated. The number of boosting iterations, which is the main tuning parameter of gradient boosting, was determined using additional ten-fold cross-validation within each of the learning samples.

The final prediction score was obtained by fitting a gradient boosting model to the complete data set, using ten-fold cross validation on the complete data to select the optimal number of boosting iterations.

\section{Results}

\section{Summary of the retrospective data}

Overall, data of 252 patients harboring 619 aneurysms were analyzed. Detailed data on patient and aneurysm characteristics is shown in Table 1.

\section{Statistical prediction model}

Figure 2 presents the percentages of correctly classified ruptures obtained from ten-fold cross-validation. Results are stratified according to patient groups having two, three etc. aneurysms. Furthermore, Fig. 2 contains the probabilities of identifying the true ruptured aneurysms by random guessing. It is seen that the correct classification rates obtained from the scoring system are substantially higher on average than the respective rates that would be obtained from random guessing. The probability of correct findings declined as the number of aneurysms increased. The only patient subgroup where the scoring system performed worse than random guessing is the group with six aneurysms. There was, however, only one patient with six aneurysms in the sample, so that the correct classification rate in this subgroup could either take the values $0 \%$ or $100 \%$. The average AUC values were $80.89 \%$ on the test data (accuracy $68.58 \%$ ), $81.94 \%$ on the training data (accuracy $68,37 \%$ ) and $82.07 \%$ on the complete data (accuracy $68,63 \%$ ), suggesting very little indication of overfitting. The final aneurysm - specific prediction score obtained from 


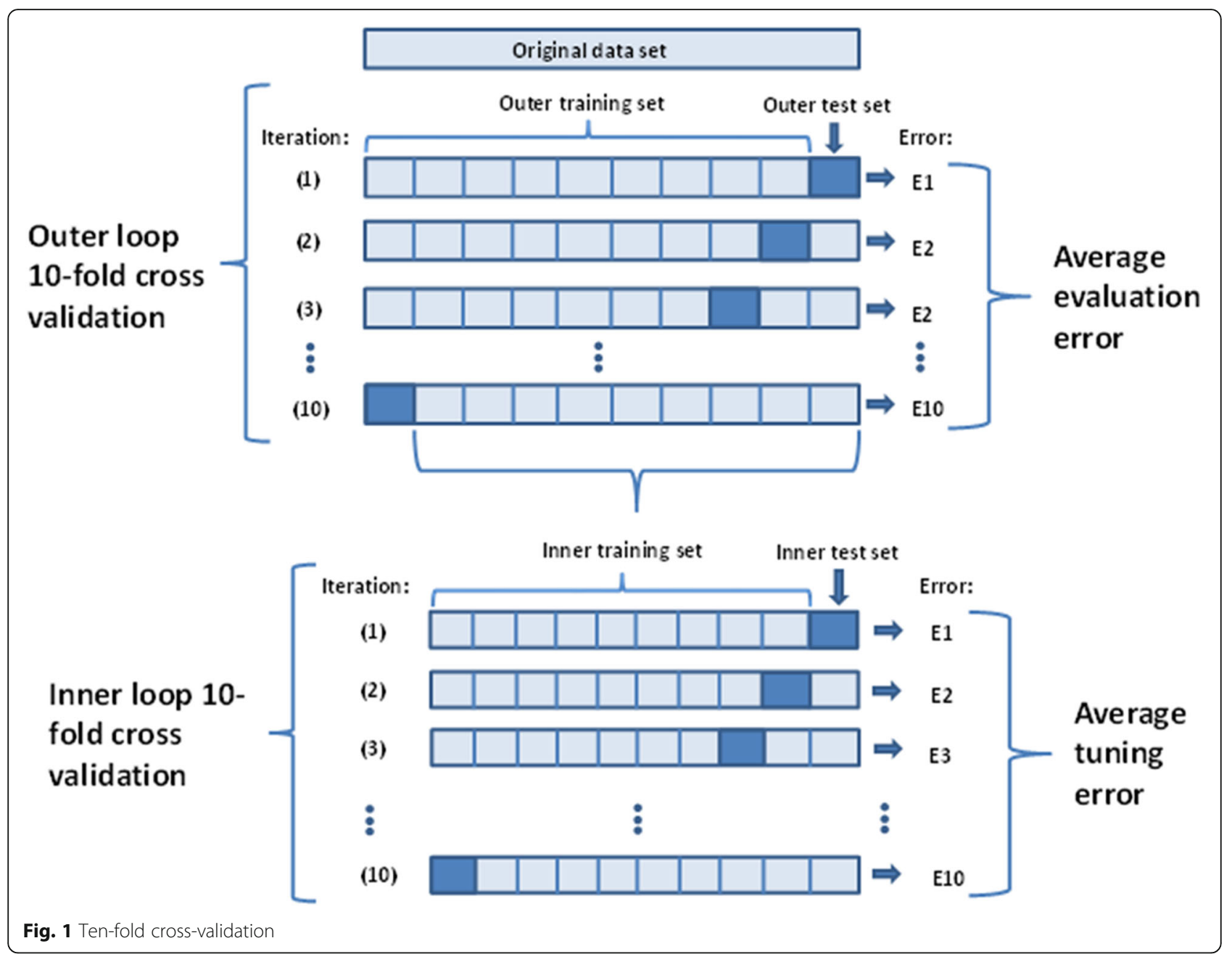

fitting a gradient boosting model to the complete data set was given by.

Aneurysm - specific prediction score $=\mathrm{A}+\mathrm{B}+\mathrm{C}$, where.

$A=0.0427 \times$ size of aneurysm $(\mathrm{mm})$.

$\mathrm{B}=0$ if Location $=\mathrm{AcomA}$ and $\mathrm{AA}$.

or -0.0104 if location $=$ PcomA.

or -0.1831 if location $=$ posterior circulation.

or -0.4055 if location $=$ MCA.

or -0.5973 if location $=$ ICA without PcomA.

$\mathrm{C}=0$ if shape $=$ regular.

or 0.5387 if shape $=$ irregular.

By definition, higher scores represent a higher risk of rupture.

In Fig. 3 the goodness of fit of the prediction score was evaluated. The fitted probabilities of the complete data set were ordered and split into 15 intervals, which each consist of 50 aneurysms except the last interval. The total number of aneurysms is not divisible by 50 and therefore the remaining aneurysms were added to the last interval. Overall, the prediction score model is well calibrated, as the estimated probabilities match closely the observed relative frequencies of rupture.

Figure 4 shows a heatmap with visual representation of the prediction score parameters.

\section{Clinical results and validation}

After the development of the statistical prediction score, prospective validation was performed utilizing patients with SAH harboring MIAs and presenting with a definitive SAH pattern admitted at the authors' institution. Cases treated endovascularly, which according to the imaging and hemorrhage pattern the bleeding source remained uncertain, so that the neurovascular team decided one-stage endovascular treatment of all possible bleeding sources, were excluded from the prospective validation. Patients with an obvious bleeding source were also included, in order to gain a larger prospective test sample, since the prediction score is applicable in all cases. Overall, 34 patients were included in the validation of the prediction score. 14 (41\%) patients underwent surgical treatment, $16(47 \%)$ patients underwent 
Table 1 Patient and aneurysm characteristics

\begin{tabular}{|c|c|c|}
\hline & & MIAs (\%) \\
\hline Pat. No. & & 252 \\
\hline Aneurysm No. & & 619 \\
\hline Sex (female/male) & & 195/57 (46/13) \\
\hline Median age $(\mathrm{y}) \pm \mathrm{SD}$ & & $53 \pm 12,8$ \\
\hline AHT (\%) & & $112(44 \%)$ \\
\hline Smoker (\%) & & $89(35 \%)$ \\
\hline Aneurysm size (mm) & & $6 \pm 5$ \\
\hline \multirow[t]{2}{*}{ Aneurysm shape } & Regular (\%) & $512(83)$ \\
\hline & irregular (\%) & $107(17)$ \\
\hline \multicolumn{3}{|c|}{ Aneurysm localization (\%) } \\
\hline$A c o m A+A A$ & & $119(19)$ \\
\hline PcomA & & $85(14)$ \\
\hline Posterior circulation & & $72(12)$ \\
\hline MCA & & $234(38)$ \\
\hline ICA w/o PcomA & & $109(17)$ \\
\hline \multicolumn{3}{|l|}{ Aneurysms frequency } \\
\hline 2 & & $174(41 \%)$ \\
\hline 3 & & 49 (11\%) \\
\hline 4 & & $22(6 \%)$ \\
\hline 5 & & $6(1 \%)$ \\
\hline 6 & & $1(1 \%)$ \\
\hline
\end{tabular}

$A H T$ arterial hypertension, $A$ com $A$ anterior communicating artery, $A A$ anterior cerebral artery, ICA internal carotid artery, MIAs multiple intracranial aneurysms, MCA middle cerebral artery, PcomA posterior communicating artery, $S A H$ subarachnoid hemorrhage, SD standard deviation, SIAs single intracranial aneurysms

endovascular treatment, 3 (9\%) patients underwent combined surgical and endovascular treatment, and 1 patient (3\%) did not underwent any treatment. Overall, 42 of 83 (50\%) aneurysms were treated in the acute phase after the ictus. In detail, 19 aneurysms were treated surgically and 23 endovascularly (Table 2).

\section{Challenging cases}

The prediction score identified the ruptured aneurysm in all 34 prospectively analyzed cases correctly, while the neurovascular team was correct in 32 cases. In two surgically treated patients (Pat. No. 9 and 24), the assumption of the neurovascular team was incorrect, while the prediction score was correct. In the first case, both aneurysms were treated surgically in the same session (MCA and AcomA), where the assumed ruptured aneurysm (MCA) was inspected and identified as unruptured, while the other aneurysm (AcomA) was identified as the bleeding source (illustrative case). In the second case, the bleeding source was uncertain for the neurovascular team. Therefore, the basilar tip artery aneurysm was treated endovascularly at first (assumed as the most likely bleeding source), and the MCA aneurysm was treated surgically secondarily. During surgical inspection, the MCA aneurysm was identified as the bleeding source.

In three other cases, patients were treated in the acute phase on their MIAs surgically. During surgical inspection the presumably ruptured aneurysm according to the prediction score, was identified as the bleeding source (Pat. No. 5, 26 and 33).

Patient 5 harbored seven aneurysms. The neurovascular team suspected the AcomA aneurysm as the bleeding source. Because of the proximity of a smaller A1 aneurysm, a clear distinction of the bleeding source was however not possible. On the other hand, the PcomA aneurysm also could not be ruled out as probable bleeding source. After coiling of the AcomA and A1 aneurysms and incomplete coiling of the PcomA aneurysm, surgical treatment of the PcomA aneurysm was decided. During surgical inspection, the AcomA aneurysm was identified as the bleeding source.

Patient 26 harbored two MCA aneurysms on the right side in proximity. Even if the size of one of them was small, surgical treatment was performed, because rupture of the smaller aneurysm could not be ruled out as bleeding source. During surgical treatment the larger one was identified as the bleeding source.

Patient 33 harbored two aneurysms (AcomA and MCA). After endovascular treatment of the AcomA aneurysm, the MCA aneurysm was treated surgically in the acute phase and did not show any sign of rupture.

Therefore, the prediction score assigned the ruptured aneurysm correctly in overall 17 patients in whom at least one aneurysm was treated surgically.

\section{Endovascularly treated patients}

In all 19 patients treated endovascularly, and in the one patient without treatment, the prediction score correlated with the assumption of the neurovascular team, and the distinct bleeding pattern in the CT-scans, indicating the ruptured aneurysm.

None of the patients treated surgically or endovascularly, suffered from rehemorrhage throughout the follow-up of 12 months.

\section{Illustrative case}

The patient was admitted with acute onset of headache at the author's institution (Fig. 5). The patient harbored two aneurysms; one regular shaped $13 \mathrm{~mm}$ aneurysm at the bifurcation of the left MCA, and one irregular shaped $5 \mathrm{~mm}$ aneurysm at the AcomA. The neurovascular team assumed the rupture of the aneurysm located at the bifurcation of the MCA, because of the pattern of the hemorrhage in the left sylvian fissure and the size of the aneurysm. After interdisciplinary decision, the patient was treated surgically. The intraoperative inspection revealed that the aneurysm located at the AcomA 


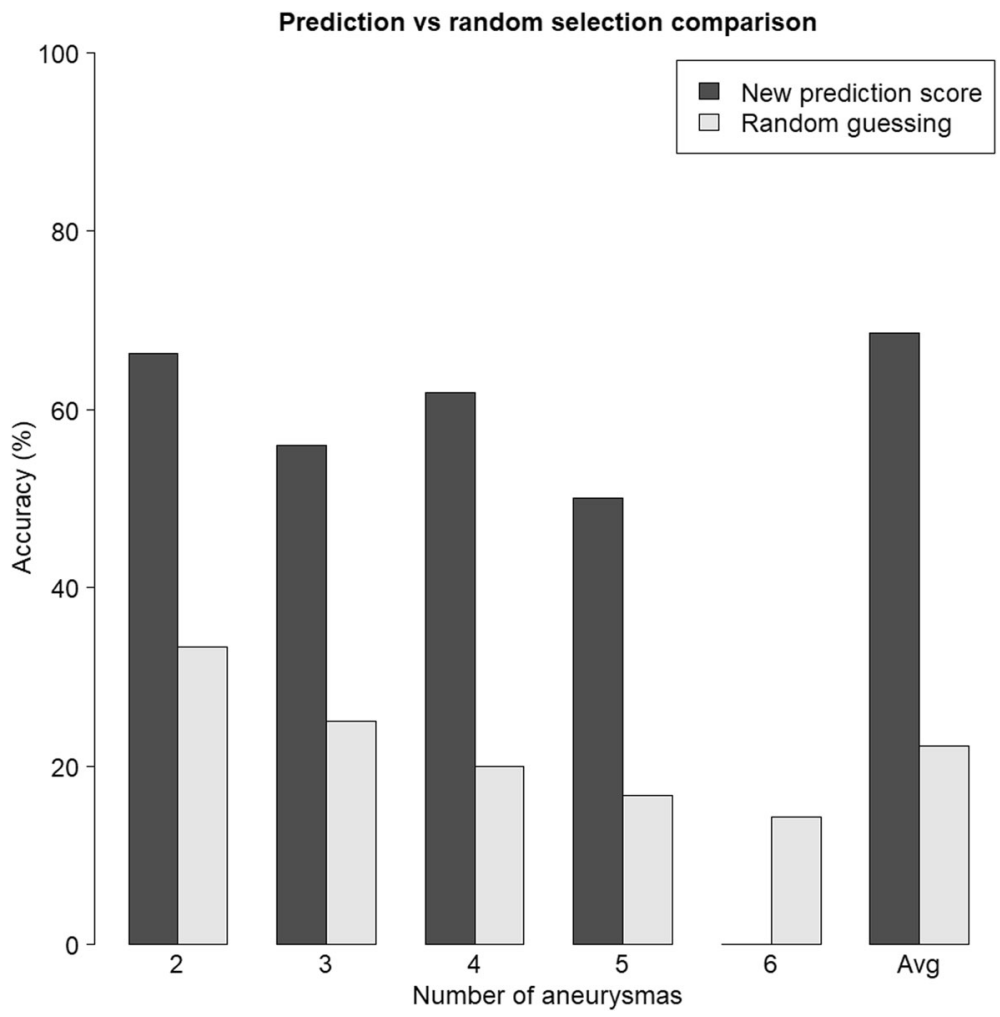

Fig. 2 Percentages of correctly classified ruptures obtained from ten-fold cross-validation and probabilities of identifying the true ruptured aneurysms by random guessing

was ruptured, and the MCA aneurysm was not. Both aneurysms were successfully treated by clipping.

\section{Score calculation}

1) AcomA: 5 (size) $\times 0.0427+0 \quad$ (location) +0.5387 (shape) $=0.7522$.

2) MCA: 13 (size) $\times 0.0427-0.4055$ (location) +0 (shape) $=0.1496$.

Therefore, the prediction score (being larger for the AcomA aneurysm) predicted correctly the ruptured aneurysm.

\section{Discussion}

Definite treatment of a ruptured aneurysm is of highest priority in patients with aneurysmal SAH $[7,8]$. In patients with SAH harboring MIAs, identifying the ruptured aneurysm may be challenging. Identification of the ruptured aneurysm in case of MIAs is ascertained from the pattern of hemorrhage and other parameters, such as shape, location and size of the aneurysm [9]. Misidentification of the ruptured aneurysm and treatment of a falsely assumed ruptured aneurysm could have major impact on the outcome of the patient, since rebleeding and severe brain injury secondary to rebleeding can occur and are known predictors of poor outcome $[10,11]$. On the other hand, treatment of additional unruptured aneurysms in patients with MIAs in the acute phase of the SAH is discussed controversially due to the risk of additional complications, and is therefore usually performed secondarily [12]. Depending on the size and location of the remaining unruptured aneurysms and the clinical condition of the patients, secondary treatment is applied in interdisciplinary consensus.

\section{Hemorrhage pattern}

Orning et al. [9] showed that in cases of definite hemorrhage pattern, where the hemorrhage is clearly lateralizing or otherwise confining to an aneurysm, identification of the ruptured aneurysm is highly accurate. However, in the same study there was a high inaccuracy in cases of nondefinite hemorrhage pattern. Uncertainty arises in cases with a diffuse and symmetric hemorrhage pattern, or a localized pattern, but with multiple aneurysms in that particular area are present in the same patient.

Because this prediction score was developed for the uncommon but usually troublesome cases, where the hemorrhage pattern does not provide any further clues for the identification of the bleeding source, CT findings were deliberately not included in the score. Given the fact that in all cases the CT findings would not provide further information, the value of this parameter would 


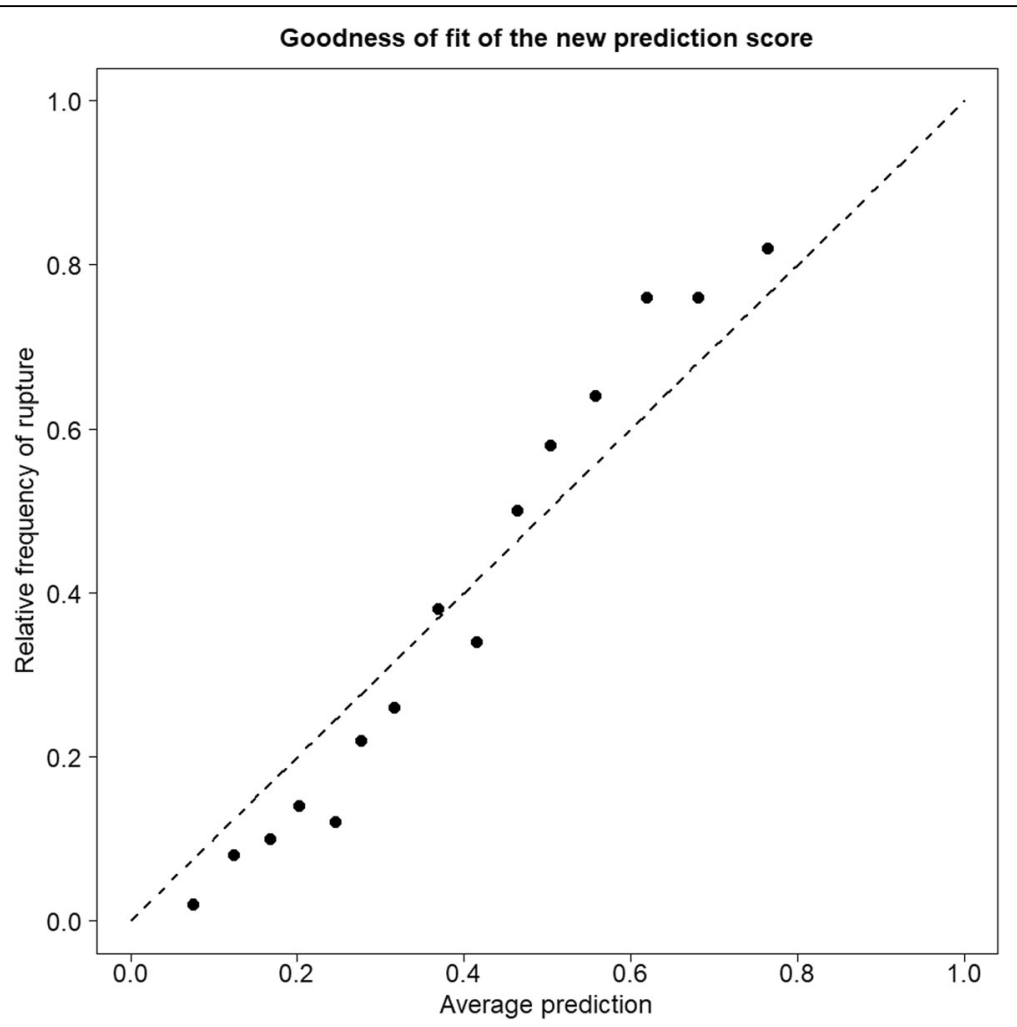

Fig. 3 Goodness of fit of the prediction score

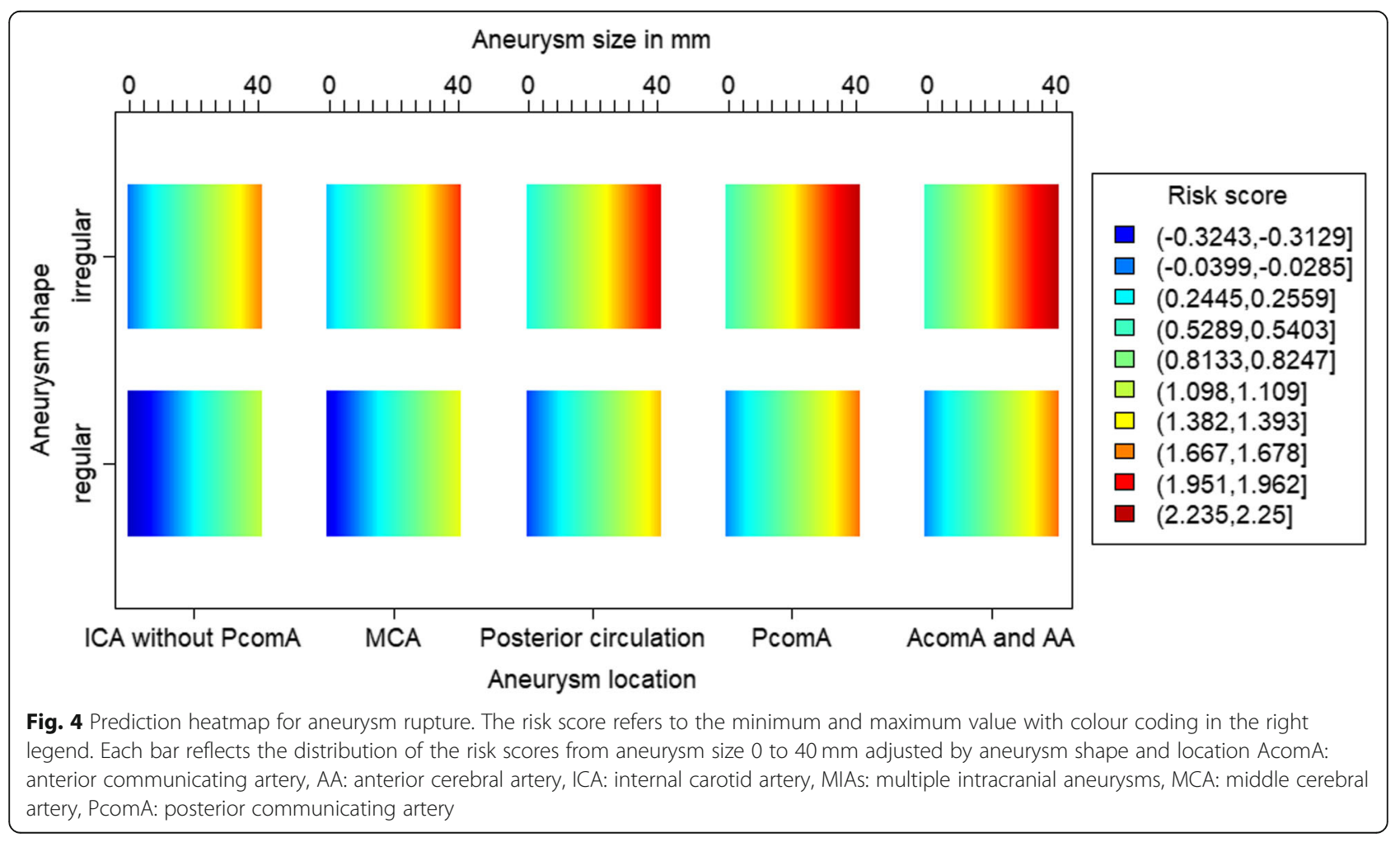


Table $\mathbf{2}$ prospective patient cohort

\begin{tabular}{|c|c|c|c|c|c|c|c|c|c|}
\hline $\begin{array}{l}\text { Pat. } \\
\text { No. }\end{array}$ & $\begin{array}{l}\text { Aneurysm } \\
\text { localisation }\end{array}$ & $\begin{array}{l}\text { Aneurysm } \\
\text { size }(\mathrm{mm})\end{array}$ & $\begin{array}{l}\text { Aneurysm } \\
\text { form }\end{array}$ & Treatment & $\begin{array}{l}\text { Expert opinion } \\
\text { before treatment }\end{array}$ & Score & $\begin{array}{l}\text { Surgical } \\
\text { Validation }\end{array}$ & $\begin{array}{l}\text { Expert } \\
\text { Validation }\end{array}$ & $\begin{array}{l}\text { Positive Score } \\
\text { Prediction (YES/NO) }\end{array}$ \\
\hline \multirow[t]{2}{*}{1} & MCA left & 7 & irregular & surgical & MCA & 0.4321 & YES & YES & YES \\
\hline & AcomA & 3 & regular & no treatment & & 0.1281 & & & \\
\hline \multirow[t]{2}{*}{2} & PcomA & 6 & regular & surgical & PcomA & 0.0216 & YES & YES & YES \\
\hline & Basilar tip & 2 & regular & no treatment & & -0.0977 & & & \\
\hline \multirow[t]{2}{*}{3} & MCA left & 7 & regular & surgical & MCA left & -0.1066 & YES & YES & YES \\
\hline & MCA right & 5 & regular & no treatment & & -0.192 & & & \\
\hline \multirow[t]{2}{*}{4} & PcomA & 6 & irregular & endovascular & PcomA & 0.7845 & NO & YES & YES \\
\hline & $\mathrm{A} 3$ & 3 & regular & no treatment & & 0.1281 & & & \\
\hline \multirow[t]{7}{*}{5} & AcomA & 7 & irregular & endovascular & AcomA & 0.8376 & YES & YES & YES \\
\hline & PcomA & 7 & regular & combined & & 0.2885 & YES & & \\
\hline & MCA & 6 & regular & no treatment & & -0.1493 & & & \\
\hline & A1 & 3 & regular & endovascular & & 0.1281 & & & \\
\hline & $\mathrm{ICA}$ & 4 & regular & no treatment & & -0.4265 & & & \\
\hline & P1 & 2 & regular & no treatment & & -0.0977 & & & \\
\hline & Basilar tip & 3 & regular & no treatment & & -0.055 & & & \\
\hline \multirow[t]{2}{*}{6} & Basilar tip & 10 & regular & endovascular & Basilar tip & 0.2439 & $\mathrm{NO}$ & YES & YES \\
\hline & Basilar side & 3 & regular & no treatment & & -0.055 & & & \\
\hline \multirow[t]{2}{*}{7} & PcomA & 6 & irregular & endovascular & PcomA & 0.7845 & NO & YES & YES \\
\hline & MCA & 4 & regular & no treatment & & -0.2347 & & & \\
\hline \multirow[t]{2}{*}{8} & AcomA & 5 & regular & endovascular & AcomA & 0.2135 & NO & YES & YES \\
\hline & MCA & 2 & regular & no treatment & & -0.3201 & & & \\
\hline \multirow[t]{2}{*}{9} & AcomA & 5 & irregular & surgical & & 0.7522 & YES & & \\
\hline & MCA & 13 & regular & surgical & MCA & 0.1496 & YES & NO & YES \\
\hline \multirow[t]{2}{*}{10} & AcomA & 3 & regular & endovascular & AcomA & 0.1281 & NO & YES & YES \\
\hline & MCA & 2 & regular & no treatment & & -0.3201 & & & \\
\hline \multirow[t]{2}{*}{11} & MCA left & 17 & regular & surgical & MCA left & 0.3204 & YES & YES & YES \\
\hline & MCA right & 7 & regular & no treatment & & -0.1066 & & & \\
\hline \multirow[t]{2}{*}{12} & Basilar tip & 6 & irregular & endovascular & Basilar tip & 0.6118 & NO & YES & YES \\
\hline & PcomA & 3 & regular & endovascular (staged treatment) & & 0.1177 & & & \\
\hline \multirow[t]{4}{*}{13} & AcomA & 3 & regular & endovascular & AcomA & 0.1281 & NO & YES & YES \\
\hline & PcomA & 3 & regular & endovascular & & 0.1177 & & & \\
\hline & OpthalmicA & 2 & regular & no treatment & & -0.5119 & & & \\
\hline & VA & 2 & regular & no treatment & & -0.0977 & & & \\
\hline \multirow[t]{3}{*}{14} & A3 & 4 & regular & endovascular & A3 & 0.1708 & NO & YES & YES \\
\hline & MCA & 3 & regular & no treatment & & -0.2774 & & & \\
\hline & MCA & 1 & regular & no treatment & & -0.3628 & & & \\
\hline \multirow[t]{2}{*}{15} & PcomA right & 8 & regular & surgical & PcomA & 0.3312 & YES & YES & YES \\
\hline & PcomA left & 4 & regular & no treatment & & 0.1604 & & & \\
\hline \multirow[t]{2}{*}{16} & MCA left & 10 & regular & surgical & MCA left & 0.0215 & YES & YES & YES \\
\hline & MCA right & 2 & regular & no treatment & & -0.3201 & & & \\
\hline \multirow[t]{2}{*}{17} & PICA left & 5 & regular & endovascular & PICA & 0.0304 & NO & YES & YES \\
\hline & SCA left & 2 & regular & no treatment & & -0.0977 & & & \\
\hline 18 & VB junction & 9 & regular & endovascular & VB junction & 0.2012 & NO & YES & YES \\
\hline
\end{tabular}


Table 2 prospective patient cohort (Continued)

\begin{tabular}{|c|c|c|c|c|c|c|c|c|c|}
\hline $\begin{array}{l}\text { Pat. } \\
\text { No. }\end{array}$ & $\begin{array}{l}\text { Aneurysm } \\
\text { localisation }\end{array}$ & $\begin{array}{l}\text { Aneurysm } \\
\text { size }(\mathrm{mm})\end{array}$ & $\begin{array}{l}\text { Aneurysm } \\
\text { form }\end{array}$ & Treatment & $\begin{array}{l}\text { Expert opinion } \\
\text { before treatment }\end{array}$ & Score & $\begin{array}{l}\text { Surgical } \\
\text { Validation }\end{array}$ & $\begin{array}{l}\text { Expert } \\
\text { Validation }\end{array}$ & $\begin{array}{l}\text { Positive Score } \\
\text { Prediction (YES/NO) } \\
\end{array}$ \\
\hline & AcomA & 4 & regular & no treatment & & 0.1708 & & & \\
\hline & A2 & 2 & regular & no treatment & & 0.0854 & & & \\
\hline \multirow[t]{2}{*}{19} & MCA right & 4 & regular & no treatment (aSDH right) & MCA right & -0.2347 & NO & YES & YES \\
\hline & MCA left & 2 & regular & no treatment & & -0.3201 & & & \\
\hline \multirow[t]{3}{*}{20} & MCA & 8 & irregular & surgical & MCA & 0.4748 & YES & YES & YES \\
\hline & $\mathrm{ICA}$ & 4 & regular & no treatment & & -0.4265 & & & \\
\hline & A3 & 3 & regular & no treatment & & 0.1281 & & & \\
\hline \multirow[t]{2}{*}{21} & MCA left & 5 & regular & surgical & MCA left & -0.192 & YES & YES & YES \\
\hline & MCA right & 5 & regular & no treatment & & -0.192 & & & \\
\hline \multirow[t]{2}{*}{22} & MCA left & 9 & irregular & surgical & MCA left & 0.5175 & YES & YES & YES \\
\hline & MCA right & 9 & regular & surgical (2 stage treatment) & & -0.0212 & YES & YES & YES \\
\hline \multirow[t]{2}{*}{23} & AcomA & 9 & irregular & endovascular & AcomA & 0.923 & NO & YES & YES \\
\hline & ICA & 7 & regular & no treatment & & -0.2984 & & & \\
\hline \multirow[t]{2}{*}{24} & Basilar tip & 6 & irregular & endovascular & & 0.6118 & NO & NO & YES \\
\hline & MCA right & 10 & regular & surgical & MCA & 0.0215 & YES & NO & YES \\
\hline \multirow[t]{3}{*}{25} & MCA right & 8 & regular & surgical & MCA right & -0.0639 & YES & YES & YES \\
\hline & MCA left & 4 & regular & no treatment & & -0.2347 & & & \\
\hline & ICA left & 4 & regular & no treatment & & -0.4265 & & & \\
\hline \multirow[t]{3}{*}{26} & MCA right & 7 & regular & surgical & MCA right & -0.1066 & YES & YES & YES \\
\hline & M2 right & 2 & regular & surgical & & -0.3201 & YES & & \\
\hline & MCA links & 3 & regular & no treatment & & -0.2774 & & & \\
\hline \multirow[t]{2}{*}{27} & PcomA left & 7 & regular & endovascular & PcomA & 0.2885 & NO & YES & YES \\
\hline & ICA right & 7 & regular & endovascular & & -0.2984 & & & \\
\hline \multirow[t]{3}{*}{28} & M2 right & 10 & regular & surgical & M2 right & 0.0215 & YES & YES & YES \\
\hline & ICA left & 6 & regular & no treatment & & -0.3411 & & & \\
\hline & M2 left & 3 & regular & no treatment & & -0.2774 & & & \\
\hline \multirow[t]{2}{*}{29} & ICA & 9 & regular & endovascular & ICA & -0.213 & NO & YES & YES \\
\hline & MCA & 3 & regular & no treatment & & -0.2774 & & & \\
\hline \multirow[t]{2}{*}{30} & PcomA & 10 & regular & endovascular & PcomA & 0.4166 & NO & YES & YES \\
\hline & AcomA & 4 & regular & no treatment & & 0.1708 & & & \\
\hline \multirow[t]{2}{*}{31} & AcomA & 11 & regular & endovascular & AcomA & 0.4697 & $\mathrm{NO}$ & YES & YES \\
\hline & PcomA & 5 & regular & no treatment & & 0.2031 & & & \\
\hline \multirow[t]{4}{*}{32} & ACA (A3) & 9 & regular & endovascular & ACA (A3) & 0.3843 & $\mathrm{NO}$ & YES & YES \\
\hline & MCA left & 3 & regular & no treatment & & -0.2774 & & & \\
\hline & ICA left & 2 & regular & no treatment & & -0.5119 & & & \\
\hline & SCA right & 6 & regular & no treatment & & 0.0731 & & & \\
\hline \multirow[t]{2}{*}{33} & AcomA & 5 & regular & endovascular & AcomA & 0.2135 & YES & YES & YES \\
\hline & M3 right & 3 & regular & surgical & & -0.2774 & YES & & \\
\hline \multirow[t]{2}{*}{34} & PcomA right & 9 & regular & surgical & PcomA & 0.3739 & YES & YES & YES \\
\hline & ICA left & 6 & regular & no treatment & & -0.3411 & & & \\
\hline
\end{tabular}

A1 segment 1 of anterior cerebral artery, $A 2$ segment 2 of anterior cerebral artery, $A 3$ segment 3 of anterior cerebral artery, $A A$ anterior cerebral artery, $A$ com $A$ anterior communicating artery, $a S D H$ acute subdural hematoma, ICA internal carotid artery, $M 2$ segment 2 of middle cerebral artery, $M 3$ segment 3 of middle cerebral artery, MCA middle cerebral artery, OphtalmicA ophthalmic artery, P1 segment 1 of posterior cerebral artery, PcomA posterior communicating artery, PICA posterior inferior cerebellar artery, SCA superior cerebellar artery, $V B$ vertebrobasilar 


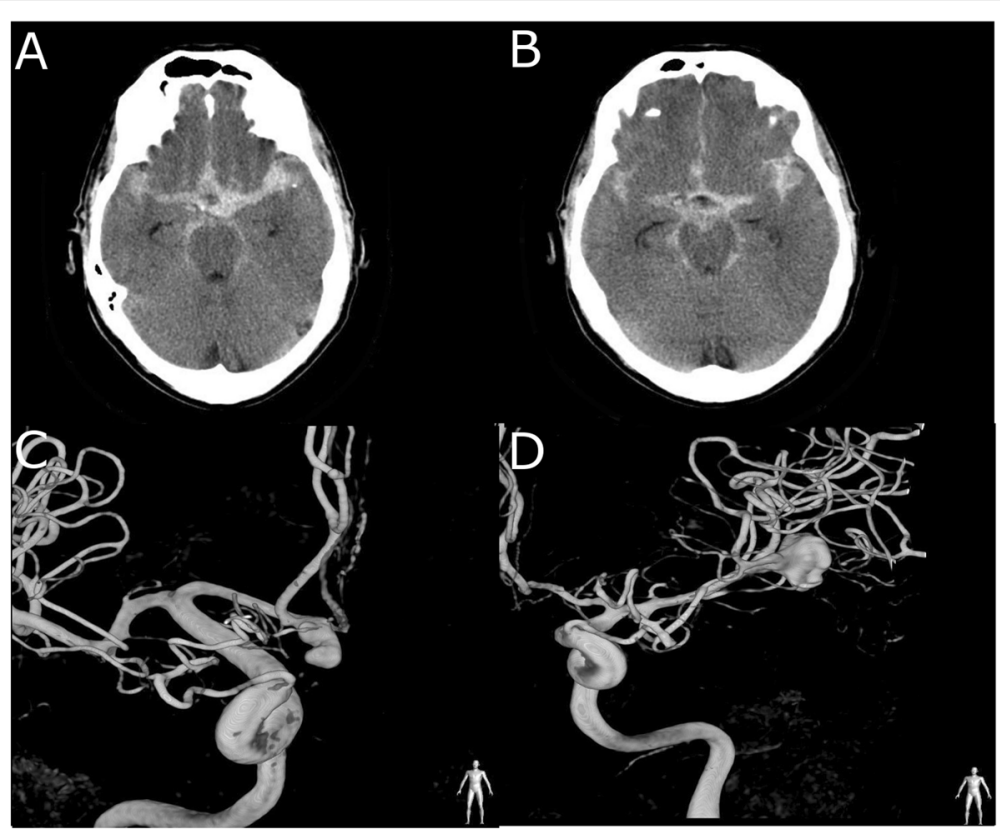

Fig. 5 Illustrative case. A and B: axial native $C T$ scan showing SAH at admission, C: DSA showing the AcomA aneurysm at admission, D: DSA showing the left MCA aneurysm at admission

be constant for each aneurysm without any influence on the score.

\section{Aneurysm size and location}

According to previous studies, size and location are postulated as independent risk factors for aneurysm rupture [13-18]. According to the ISUIA trial, aneurysms located at the posterior circulation including the PcomA, have a higher possibility of rupture [15]. However, Juvela et al. postulated that aneurysms located at the ACA were at significant risk to rupture [1]. In patients with MIAs, aneurysms located at the AcomA had the highest probability to rupture according to Nehls et al. [3].

According to the findings of the present study, the site with the highest probability of a ruptured aneurysm in patients harboring MIAs was the AA including the AcomA. Furthermore, aneurysm size was also identified to be a risk factor for aneurysm rupture.

Backes et al. [19] reported that the ruptured aneurysm in patients with MIAs was not the largest aneurysm in $29 \%$ of the patients. Therefore, the use of aneurysm size or aneurysm location alone seems not to predict the ruptured aneurysm adequately.

\section{Aneurysm shape}

Irregular aneurysm shape is considered to be associated with aneurysm enlargement which is a surrogate parameter for aneurysm rupture [20, 21]. Backes et al. [19] described this parameter as a factor for aneurysm rupture independent of aneurysm size, location and patient characteristics in MIAs. Maslehaty et al. [22] investigated the anatomical factors in cases of MCA mirror aneurysms and showed that size and shape were predictive for rupture in their series. Nehls et al. found, that irregularity of the aneurysm morphology was more indicative for the ruptured aneurysm than size [3]. In the present study, irregular shaped aneurysms were also found to rupture more likely compared to regularly shaped aneurysms.

\section{Clinical setting and use of the prediction score}

Aim of the development of the scoring system was to create a simple tool, to identify the ruptured aneurysm in patients with MIAs and unclear bleeding pattern in cases of SAH. We only used readily available data, that was accessible using CT-A or DSA. Therefore, the described prediction score can easily be assessed and used in the clinical setting. According to our findings and experience using the prediction score, for example in the illustrative case, it can provide additional information and improve the treatment decision. The score is developed to be used in cases with diffuse $\mathrm{SAH}$, without distinct bleeding pattern pointing out the bleeding source. In the prospective validation dataset, five of the cases $(15 \%)$ were challenging in respect of defining the bleeding source. In all these challenging cases, for which the prediction score was initially developed, the bleeding source was identified correctly. In contrast, the neurovascular team predicted the true bleeding source in three of the five patients correctly. Given the uncertainty in 
some challenging cases, treatment of all possible bleedings sources was performed. The true value of the prediction score might be in troublesome cases, where treatment of multiple aneurysms might not be easily feasible due to aneurysm or patient specific characteristics. The prediction model can provide additional information for the decision-making process.

\section{Limitations}

The score was derived from a retrospective dataset of the authors institution and was then prospectively validated at the same center. Furthermore, the prospective validated score was conducted with a relatively small number of patients, since patients harboring MIAs with SAH represent just a small fraction of all SAH patients and the troublesome cases with non-definite bleeding pattern are infrequent. The prediction score was additionally validated with endovascularly treated aneurysms, in order to gain a greater number of patients. In all patients treated endovascularly, the bleeding pattern pointed unambiguously the ruptured aneurysm. However, if only the surgically treated aneurysms were to be included in the validation, the correctness of the prediction score would remain by $100 \%$.

The score is not intended to replace the expert's decision. It is supposed to be a cornerstone for further multicenter prospective studies for its validation, where afterwards it can be used to support neurovascular team's decisions. Given the fact that the challenging cases needed for prospective validation are overall rare, multicenter independent data is necessary.

\section{Conclusions}

This simple prediction score might provide support for neurovascular teams for treatment decision in SAH patients harboring multiple intracranial aneurysms and no definite hemorrhage pattern in order to identify the ruptured aneurysm. However, larger cohorts for prospective evaluation are warranted.

\section{Disclosures}

The authors report no conflict of interest concerning the materials or methods used in this study or the findings specified in this paper.

\footnotetext{
Abbreviations

A1: Segment 1 of anterior cerebral artery; A2: Segment 2 of anterior cerebral artery; A3: Segment 3 of anterior cerebral artery; AA: Anterior cerebral artery; AcomA: Anterior communicating artery; AHT: Hypertension; aSDH: Acute subdural hematoma; CT: Computed tomography; CT-A: CT - angiography; DSA: Digital subtraction angiography; ICA: Internal carotid artery; $\mathrm{ICH}$ : Intracerebral hemorrhage; M2: Segment 2 of middle cerebral artery; M3: Segment 3 of middle cerebral artery; MCA: Middle cerebral artery; MIAs: Multiple intracranial aneurysms; OphtalmicA: Ophthalmic artery; P1: Segment 1 of posterior cerebral artery; PcomA: Posterior communicating artery; PICA: Posterior inferior cerebellar artery; SAH: Subarachnoid hemorrhage; SCA: Superior cerebellar artery; VB: Vertebrobasilar
}

\section{Acknowledgements}

None.

\section{Ethic approvals and consent to participate}

All aspects of this study were approved by the ethics committee of the Rheinische Friedrich-Wilhelms-University, Bonn, Germany. The appropriate permissions to access the patient database which provided the data for our study were granted by the Department of Neurosurgery, Rheinische FriedrichWilhelms-University, Bonn, Germany and approved by the local ethics committee (No.: 331/12). All procedures performed in studies involving human participants were in accordance with the ethical standards of the institutional and national research committee and with the 1964 Helsinki declaration and its later amendments or comparable ethical standards.

\section{Authors' contributions}

E.G and A. H designed the study. A. H, P. S and S. B collected, analyzed and interpreted data. A. H wrote the initial paper and E. G revised the paper. T. W and M. S performed statistical analyses. P. S, E. G, M. S and H. V revised the paper for intellectual content. All authors read and approved the final manuscript.

\section{Funding}

None.

\section{Availability of data and materials}

The datasets used and/or analyzed during the current study are available from the corresponding author on reasonable request.

\section{Consent for publication}

Not applicable.

\section{Competing interests}

The authors declare that they have no competing interests.

\section{Author details}

${ }^{1}$ Department of Neurosurgery, Rheinische Friedrich-Wilhelms-University, Sigmund-Freud-Str. 25, 53127 Bonn, Germany. ${ }^{2}$ Institute for Medical Biometry, Informatics and Epidemiology, Faculty of Medicine, Rheinische

Friedrich-Wilhelms-University, Bonn, Germany.

Received: 20 July 2019 Accepted: 25 February 2020

Published online: 29 February 2020

\section{References}

1. Juvela S, Poussa K, Lehto H, Porras M. Natural history of unruptured intracranial aneurysms: a long-term follow-up study. Stroke. 2013;44:241421. https://doi.org/10.1161/STROKEAHA.113.001838.

2. Kaminogo M, Yonekura M, Shibata S. Incidence and outcome of multiple intracranial aneurysms in a defined population. Stroke. 2002;34:16-21. https://doi.org/10.1161/01.str.0000046763.48330.ad.

3. Nehls DG, Flom RA, Carter LP, Spetzler RF. Multiple intracranial aneurysms: determining the site of rupture. J Neurosurg. 1985;63:342-8. https://doi.org/ 10.3171/jns.1985.63.3.0342.

4. Bühlmann $P$, Hothorn T. Boosting algorithms: regularization, prediction and model fitting. Stat Sci. 2007;22:477-505. https://doi.org/10.1214/07-sts242.

5. Kneib T, Hothorn T, Tutz G. Variable selection and model choice in geoadditive regression models. Biometrics. 2009;65:626-34. https://doi.org/ 10.1111/j.1541-0420.2008.01112.x.

6. Hastie T, Tibshirani R, Friedman J. The Elements of Statistical Learning. 2nd ed: 2009.

7. Connolly ES Jr, Rabinstein AA, Carhuapoma JR, Derdeyn CP, Dion J, Higashida RT, Hoh BL, Kirkness CJ, Naidech AM, Ogilvy CS, Patel AB, Thompson BG, Vespa P, American Heart Association Stroke C, Council on Cardiovascular R, Intervention, Council on Cardiovascular N, Council on Cardiovascular S, Anesthesia, Council on Clinical C. Guidelines for the management of aneurysmal subarachnoid hemorrhage: a guideline for healthcare professionals from the American Heart Association/american Stroke Association. Stroke. 2012;43:1711-37. https://doi.org/10.1161/STR. Ob013e3182587839.

8. Siddiq F, Chaudhry SA, Tummala RP, Suri MF, Qureshi Al. Factors and outcomes associated with early and delayed aneurysm treatment in subarachnoid hemorrhage patients in the United States. Neurosurgery. 
2012;71:670-7; discussion 677-678. https://doi.org/10.1227/NEU. 0b013e318261749b.

9. Orning JL, Shakur SF, Alaraj A, Behbahani M, Charbel FT, Aletich VA, AminHanjani S. Accuracy in identifying the source of subarachnoid hemorrhage in the setting of multiple intracranial aneurysms. Neurosurgery. 2017. https://doi.org/10.1093/neuros/nyx339.

10. Hino A, Fujimoto M, Iwamoto Y, Yamaki T, Katsumori T. False localization of rupture site in patients with multiple cerebral aneurysms and subarachnoid hemorrhage. Neurosurgery. 2000;46:825-30.

11. Zhao B, Fan Y, Xiong Y, Yin R, Zheng K, Li Z, Tan X, Yang H, Zhong M, Group AS. Aneurysm rebleeding after poor-grade aneurysmal subarachnoid hemorrhage: predictors and impact on clinical outcomes. J Neurol Sci. 2016; 371:62-6. https://doi.org/10.1016/j.jns.2016.10.020.

12. Rinne J, Hernesniemi J, Niskanen M, Vapalahti M. Management outcome for multiple intracranial aneurysms. Neurosurgery. 1995:36:31-7 discussion 37-38.

13. Andreoli A, Sturiale C, Pozzati E, Mascari C, Testa C. Unruptured cerebral aneurysms. What is the risk of rupture? What is the risk connected with a surgical intervention? A contribution to the international ISUIA study: international study on Unruptured intracranial aneurysms. Recenti Prog Med. 1999;90:249-53.

14. Guresir E, Vatter H, Schuss P, Platz J, Konczalla J, de Rochement RM, Berkefeld J, Seifert V. Natural history of small unruptured anterior circulation aneurysms: a prospective cohort study. Stroke. 2013;44:3027-31. https://doi. org/10.1161/STROKEAHA.113.001107.

15. Ishibashi T, Murayama Y, Urashima M, Saguchi T, Ebara M, Arakawa H, Irie K, Takao H, Abe T. Unruptured intracranial aneurysms: incidence of rupture and risk factors. Stroke. 2009;40:313-6. https://doi.org/10.1161/STROKEAHA. 108.521674.

16. Juvela S. Risk factors for multiple intracranial aneurysms. Stroke. 2000;31:392-7.

17. Morita AKT, Hashi K, Aoki N, Fukuhara S, Hashimoto N, Nakayama T, Sakai M, Teramoto A, Tominari S, Yoshimoto T. The natural course of Unruptured cerebral. N Engl J Med. 2012;366:2474-82.

18. Sonobe M, Yamazaki T, Yonekura M, Kikuchi H. Small unruptured intracranial aneurysm verification study: SUAVe study, Japan. Stroke. 2010;41:1969-77. https://doi.org/10.1161/STROKEAHA.110.585059.

19. Backes D, Vergouwen MD, Velthuis BK, van der Schaaf IC, Bor AS, Algra A, Rinkel GJ. Difference in aneurysm characteristics between ruptured and unruptured aneurysms in patients with multiple intracranial aneurysms. Stroke. 2014:45:1299-303. https://doi.org/10.1161/STROKEAHA.113.004421..

20. Bor AS, Tiel Groenestege AT, terBrugge KG, Agid R, Velthuis BK, Rinkel GJ, Wermer MJ. Clinical, radiological, and flow-related risk factors for growth of untreated, unruptured intracranial aneurysms. Stroke. 2015;46:42-8. https:// doi.org/10.1161/STROKEAHA. 114.005963.

21. Phan TG, Huston J 3rd, Brown RD Jr, Wiebers DO, Piepgras DG. Intracranial saccular aneurysm enlargement determined using serial magnetic resonance angiography. J Neurosurg. 2002;97:1023-8. https://doi.org/10. 3171/jns.2002.97.5.1023.

22. Maslehaty H, Capone C, Frantsev R, Fischer I, Jabbarli R, Cornelius JF, Kamp MA, Cappabianca P, Sure U, Steiger HJ, Petridis AK. Predictive anatomical factors for rupture in middle cerebral artery mirror bifurcation aneurysms. J Neurosurg. 2017:1-9. https://doi.org/10.3171/2017.2.JNS162705.

\section{Publisher's Note}

Springer Nature remains neutral with regard to jurisdictional claims in published maps and institutional affiliations.

Ready to submit your research? Choose BMC and benefit from:

- fast, convenient online submission

- thorough peer review by experienced researchers in your field

- rapid publication on acceptance

- support for research data, including large and complex data types

- gold Open Access which fosters wider collaboration and increased citations

- maximum visibility for your research: over $100 \mathrm{M}$ website views per year

At BMC, research is always in progress.

Learn more biomedcentral.com/submissions 